\title{
An Evaluation of Antibodies and Clinical Resistance to Salmon Calcitonin
}

\author{
Frederick R. Singer, J. Phillip Aldred, Robert M. Neer, \\ Stephen M. Krane, John T. Potts, Jr., and Kurt J. Bloch \\ From the Department of Medicine, Massachusetts General Hospital, \\ Boston 02114, West Roxbury Veterans Administration Hospital, West Roxbury, \\ Massachusetts 02132, and Harvard Medical School, Boston 02115, and the \\ Armour Pharmaceutical Co., Kankakee, Illinois 60901
}

\begin{abstract}
A B S T R A C T 21 patients with Paget's disease of bone and one with osteoporosis were studied to detect development of antibodies to salmon calcitonin during chronic therapy. Antibody titers ranged from $1: 40$ to $1: 30,000$ in plasma obtained after treatment of 11 patients. Radioimmunoelectrophoresis revealed that the antibodies were restricted to the $\gamma \mathrm{G}$ class. One patient, W. O., with Paget's disease initially responded to treatment with a decrease in bone turnover, but later became resistant to the hormone in association with the appearance of a very high titer $(1: 30,000)$ of antibody against salmon calcitonin. A $1: 10$ dilution of his plasma was shown to completely inactivate $20 \mathrm{mMRC}$ units $/ \mathrm{ml}$ of salmon calcitonin as detected by bioassay in rats; slight inactivation was detected at a 1:200 dilution. All other patients continued to respond to salmon calcitonin despite the development of antibody to the hormone in ten cases. No evidence of systemic allergic reactions or other toxicity was found in any patient. The data suggest that although antibody formation may occur in as many as $50 \%$ of patients treated with salmon calcitonin, this antibody response is unlikely to be of clinical significance in most patients. However, in an occasional patient, a marked antibody response may occur which interferes with the therapeutic use of the hormone.
\end{abstract}

\section{INTRODUCTION}

Calcitonin (porcine) was first administered to man in 1966 (1). Since then porcine, salmon, and human cal-

This work was presented in part to the American Federation for Clinical Research, Carmel, Calif., 3 February 1972.

Dr. Singer is a clinical investigator of the Veterans Administration. His present address is Wadsworth Hospital, Los Angeles, Calif.

Recciacd for publication 18 February $19 \pi 2$ and in resised form 18 April 1972 . citonin have been used to treat patients with a variety of skeletal diseases. It is now well established that the hormone is useful in the suppression of increased skeletal turnover in patients with Paget's disease of bone (2-4). We have treated 22 patients with salmon calcitonin for periods up to 19 months and have tested serial blood samples from these patients to detect antibody to salmon calcitonin. Since salmon calcitonin differs in structure from human calcitonin, treatment with the former might stimulate formation of such antibodies (5). We now report the development of antibodies in $50 \%$ of the tested patients. One patient became resistant to salmon calcitonin in association with the development of a high titer of antibodies; the other patients had low titers of antibody and continued to respond to the hormone.

\section{METHODS}

Clinical. 21 patients with Paget's disease and one with steroid-induced osteoporosis received daily subcutaneous injections of salmon calcitonin from 1.5 to 19 months. The age and sex of the patients, duration of treatment, and dose of hormone administered are shown in Table I. Initially, the patients were treated with natural salmon calcitonin, ${ }^{1}$ and later synthetic salmon calcitonin. ${ }^{2}$ The hormone was dissolved in $16 \%$ gelatin and administered subcutaneously once daily. Gelatin was used in an attempt to prolong the action of the hormone, as had previously been demonstrated in animal studies (6). $5 \mathrm{mg}$ of phenol was present in each milliliter of diluent; inclusion of this preservative permitted the use of a multiple dose vial. Two patients (L. H. and A. R.) developed localized redness and itching at the injection sites; for these patients an acetatebuffered diluent was employed; after 3 months in patient L. H., and after 5 days of treatment in patient A. R.

Laboratory. The continued biochemical response to calcitonin after chronic administration was assessed by measuring the plasma calcium (7) serially for $24 \mathrm{hr}$ after the initial and selected subsequent injections; the $24 \mathrm{hr}$ urinary hydroxyproline excretion (8), and the plasma alkaline phos-

${ }^{1}$ AL1025 (Armour Pharmaceutical Co., Kankakee, I1l.).

${ }^{2}$ AL0977 (Armour Pharmaceutical Co.). 
TABLE I

Clinical Data on 22 Patients Treated with Salmon Calcitonin

\begin{tabular}{|c|c|c|c|c|c|c|}
\hline & Patient & Sex & Age & Dose & $\begin{array}{l}\text { Duration } \\
\text { of } \\
\text { therapy }\end{array}$ & $\begin{array}{l}\text { Salmon cal- } \\
\text { citonin-125I } \\
\text { binding } \\
\text { titer }\end{array}$ \\
\hline \multicolumn{7}{|c|}{ Paget's disease } \\
\hline 1. & W. O. & M & 51 & 100 & 15 & $1: 30,000$ \\
\hline 2. & A. M. & $\mathrm{F}$ & 63 & 50 & 7 & $1: 1500$ \\
\hline 3. & M. K. & $\mathrm{F}$ & 53 & 50 & 10 & $1: 1500$ \\
\hline 4. & J. A. & M & 61 & 20 & 11.5 & $1: 500$ \\
\hline 5. & R. W. & $\mathrm{F}$ & 59 & 20 & 5 & $1: 500$ \\
\hline 6. & H. H. & M & 50 & 100 & 11 & $1: 500$ \\
\hline 7. & M. D. & $\mathrm{F}$ & 49 & 100 & 7.5 & $1: 400$ \\
\hline 8. & G. O. & $\mathrm{F}$ & 47 & 100 & 7.5 & $1: 400$ \\
\hline 9. & A. F. & M & 56 & 100 & 16 & $1: 200$ \\
\hline 10. & L. H. & $\mathrm{F}$ & 70 & 50 & 12 & $1: 125$ \\
\hline 11. & A. R. & $\mathrm{F}$ & 59 & 100 & 5 & $1: 40$ \\
\hline 12. & G. C. & $\mathrm{F}$ & 50 & $50-500$ & 19 & $<1: 5$ \\
\hline 13. & P.S. & M & 78 & $50-100$ & 12 & $<1: 5$ \\
\hline 14. & C. E. & $\mathrm{F}$ & 57 & 50 & 10 & $<1: 5$ \\
\hline 15. & H. B. & $\mathrm{F}$ & 58 & 20 & 9 & $<1: 5$ \\
\hline 16. & F. K. & F & 71 & 50 & 7.5 & $<1: 5$ \\
\hline 17. & G. Z. & $\mathrm{F}$ & 67 & 50 & 7 & $<1: 5$ \\
\hline 18. & B. B. & M & 40 & 10 & 4 & $<1: 5$ \\
\hline 19. & F. M. & M & 55 & 20 & 3.5 & $<1: 5$ \\
\hline 20. & I. D. & $\mathrm{F}$ & 60 & 50 & 2.5 & $<1: 5$ \\
\hline 21. & L. C. & $\mathrm{F}$ & 50 & 100 & 1.5 & $<1: 5$ \\
\hline \multicolumn{7}{|c|}{ Osteoporosis } \\
\hline & J. C. & M & 58 & 100 & 12 & $<1: 5$ \\
\hline
\end{tabular}

* MRC units, daily dose.

phatase concentrations (9) were measured 5-7 days before the start of treatment and for similar periods of time at intervals of several months during treatment. Renal, hepatic, and hematologic function was assessed by the usual laboratory tests. Levels of parathyroid hormone in plasma were measured by radioimmunoassay (10) using plasma obtained in the basal state, after the first injection of salmon calcitonin, and during treatment.

Plasma binding of salmon calcitonin- ${ }^{125} I$. Plasma was obtained before and at intervals during treatment $(24 \mathrm{hr}$ after injection), and stored at $-4^{\circ} \mathrm{C}$. Salmon calcitonin was iodinated with ${ }^{125} \mathrm{I}$ by the method of Hunter and Greenwood (11) and the labeled peptide was purified by absorption and eluation from silica (12). The specific activity of the salmon calcitonin- ${ }^{125} \mathrm{I}$ was $150-350 \mu \mathrm{Ci} / \mu \mathrm{g}$. To detect binding of salmon calcitonin ${ }^{125} \mathrm{I}$ to a plasma component, multiple dilutions of plasma were incubated at $4^{\circ} \mathrm{C}$ with 30 pg salmon calcitonin- ${ }^{125} \mathrm{I}$ at $\mathrm{pH} 7$ in $0.02 \mathrm{M}$ phosphate buffer containing $16 \%$ pooled human plasma by volume ${ }^{3}$ for $48-72$ hr. Final incubation volume was $0.5 \mathrm{ml}$. Control tubes containing the same dilutions of plasma and $30 \mathrm{pg}$ salmon calcitonin- ${ }^{125} \mathrm{I}$ were incubated simultaneously with excess unlabeled salmon calcitonin. Separation of bound from free hormone was accomplished by addition of $1 \mathrm{ml}$ of dioxane,

\footnotetext{
${ }^{3}$ The pooled human plasma is used as a part of a standard diluent in our calcitonin radioimmunoassays; this plasma was separately shown not to bind salmon calcitonin.
}

incubation for $30 \mathrm{~min}$, and centrifugation at $10,000 \mathrm{rpm}$ at $4^{\circ}$ for $10 \mathrm{~min}$. The supernatant was decanted and the radioactivity in the dioxane precipitate (bound fraction) and supernatant (free fraction) was measured in a gamma spectrometer (Packard Instrument Co., Inc., Downers Grove, Ill.). The ratio of bound to free salmon calcitonin${ }^{125}$ I was calculated using a correction for nonspecific binding determined from the control tubes. The formula used is as follows :

$$
\operatorname{Corrected} \frac{B}{F}=\frac{B-\left[(B+F)\left(\frac{B_{c}}{B_{c}+F_{c}}\right)\right]}{F},
$$

where $\mathrm{B}=$ bound $\mathrm{cpm}$ in presence of patient's plasma, $\mathrm{F}=$ free $\mathrm{cpm}$ in presence of patient's plasma, $\mathrm{B}_{\mathrm{c}}=$ bound $\mathrm{cpm}$ in presence of patient's plasma + excess salmon calcitonin, $F_{c}$ $=$ free $\mathrm{cpm}$ in presence of patient's plasma + excess salmon calcitonin. The plasma binding titer is then defined as the highest dilution of plasma at which specific binding, i.e., a corrected $\mathrm{B} / \mathrm{F}$ of 0.05 , could be demonstrated.

The maximum binding capacity of plasma (13) from patient $\mathrm{W}$. O. was determined by incubating a $1: 50$ dilution of plasma obtained after $1 \mathrm{yr}$ of treatment with 30 pg salmon calcitonin- ${ }^{-25} \mathrm{I}$ plus amounts of unlabeled salmon calcitonin ranging from 0 to $100 \mathrm{ng} / \mathrm{ml}$ for $96 \mathrm{hr}$ at $4^{\circ} \mathrm{C}$. Separation of bound from free hormone was accomplished as before. The data was analyzed by plotting the ratio of bound to free hormone as a function of salmon calcitonin bound and extrapolating to the abscissa.

Characterization of plasma binding. Electrophoresis in agarose gel of control and treatment plasma mixed with salmon calcitonin- ${ }^{125} \mathrm{I}$ was performed according to Laurell (14). Immuno- and radioimmunoelectrophoresis were performed as previously described (15), except that X-ray film was applied to the dry plates for 4-6 days. Monospecific antisera to human $\mathrm{G}, \mathrm{A}$, and $\mathrm{M}$ immunoglobulins were prepared according to the method of Fahey and McLaughlin (16).

Inactivation of salmon calcitonin by plasma. Plasma samples were also tested to detect inhibition of the hypocalcemic activity of salmon calcitonin by bioassay; control and treatment plasma were examined from six patients. All plasma samples were heated to $56^{\circ} \mathrm{C}$ for $20 \mathrm{~min}$, since it is known this will eliminate the factor in plasma that normally inactivates calcitonin (17). To $500,250,100,50$, and $25 \mu \mathrm{l}$ of plasma was added $100 \mathrm{mMRC}$ units (Medical Research Council units) of salmon calcitonin in $1 \%$ gelatin solution, and the total volume adjusted to $5.0 \mathrm{ml}$ with $0.9 \% \mathrm{NaCl}$. These quantities of plasma represent an effective dilution of $1: 10$ to $1: 200$. After thorough mixing, samples were incubated at room temperature for $30 \mathrm{~min}$, and then analyzed by a modification of a standard rat bioassay for calcitonin (18). Each dilution of plasma was injected subcutaneously into six fasted female SpragueDawley rats so as to administer a dose of $10 \mathrm{mMRC}$ units $/ 100$ grams in $0.5 \mathrm{ml}$ diluent to each rat. After 30 min, the rats were anesthetized with ether, blood was obtained from the abdominal aorta, and after centrifugation, the concentration of serum calcium was determined (19).

The plasma of patient $\mathrm{W}$. O. was studied in triplicate. The fall in serum calcium (mean $\pm \mathrm{SE}$ ) at 30 min was plotted for each dilution of plasma studied, including a $1: 10$ plasma dilution from a normal subject. In order to estimate the dilution of plasma which would completely inactivate the salmon calcitonin injected, the data were ana- 
lyzed by plotting the per cent inhibition of the maximal hypocalcemic response (the response obtained with the $1: 10$ control plasma) against the plasma dilution on a $\log$ scale. A regression line was drawn which was extended through $100 \%$ inhibition to obtain the estimate.

\section{RESULTS}

Plasma binding of salmon calcitonin- ${ }^{125} I$. The results of tests with plasma from each of the 22 patients are listed in Table I. Nonspecific binding of salmon calcitonin $-{ }^{125} \mathrm{I}$, the fraction of labeled hormone that could not be displaced from plasma by excess unlabeled salmon calcitonin, did not exceed $20 \%$ in any of the patients. The control samples of plasma obtained from each patient before treatment in all instances did not bind salmon calcitonin- ${ }^{125} \mathrm{I}$. In samples obtained from 10 patients, the binding after treatment was detected at dilutions of plasma that ranged from $1: 40$ to $1: 1500$. The 11th patient, W. O., with a distinctly higher titer of $1: 30,000$, followed a unique clinical course that suggested possible inactivation of salmon calcitonin by antibody.

Case summary. W. O. (MGH No. 128-18-92) is a
50 yr old patient with Paget's disease involving the skull and pelvis. He had mild loss of hearing and pelvic pain. He was treated with $100 \mathrm{MRC}$ units of salmon calcitonin daily in $0.5 \mathrm{ml}$ gelatin diluent for 15 months. Fig. 1 illustrates the result of this treatment on plasma alkaline phosphatase and urinary total hydroxyproline excretion over an 11.5 month period. During this time his alkaline phosphatase and hydroxyproline excretion decreased and then rose to pretreatment levels. Concomitant with the reversal of the initial response, was a marked increase in his plasma binding titer of salmon calcitonin ${ }^{125} \mathrm{I}$. Fig. 2 indicates his plasma calcium response up to $12 \mathrm{hr}$ after his first injection of salmon calcitonin and intermittently during treatment. Although he initially had a hypocalcemic response of $1 \mathrm{mg} / 100 \mathrm{ml}$ after a test dose of $20 \mathrm{MRC}$ units (Fig. 2A), he no longer became hypocalcemic after $100 \mathrm{MRC}$ units of salmon calcitonin at 7.5 months (Fig. 2B). After $1 \mathrm{yr}$ of treatment, a rapid i.v. injection of $1000 \mathrm{MRC}$ units did lower plasma calcium (Fig. $2 C$ ), but 1000 MRC units subcutaneously did not (Fig. $2 D)$.
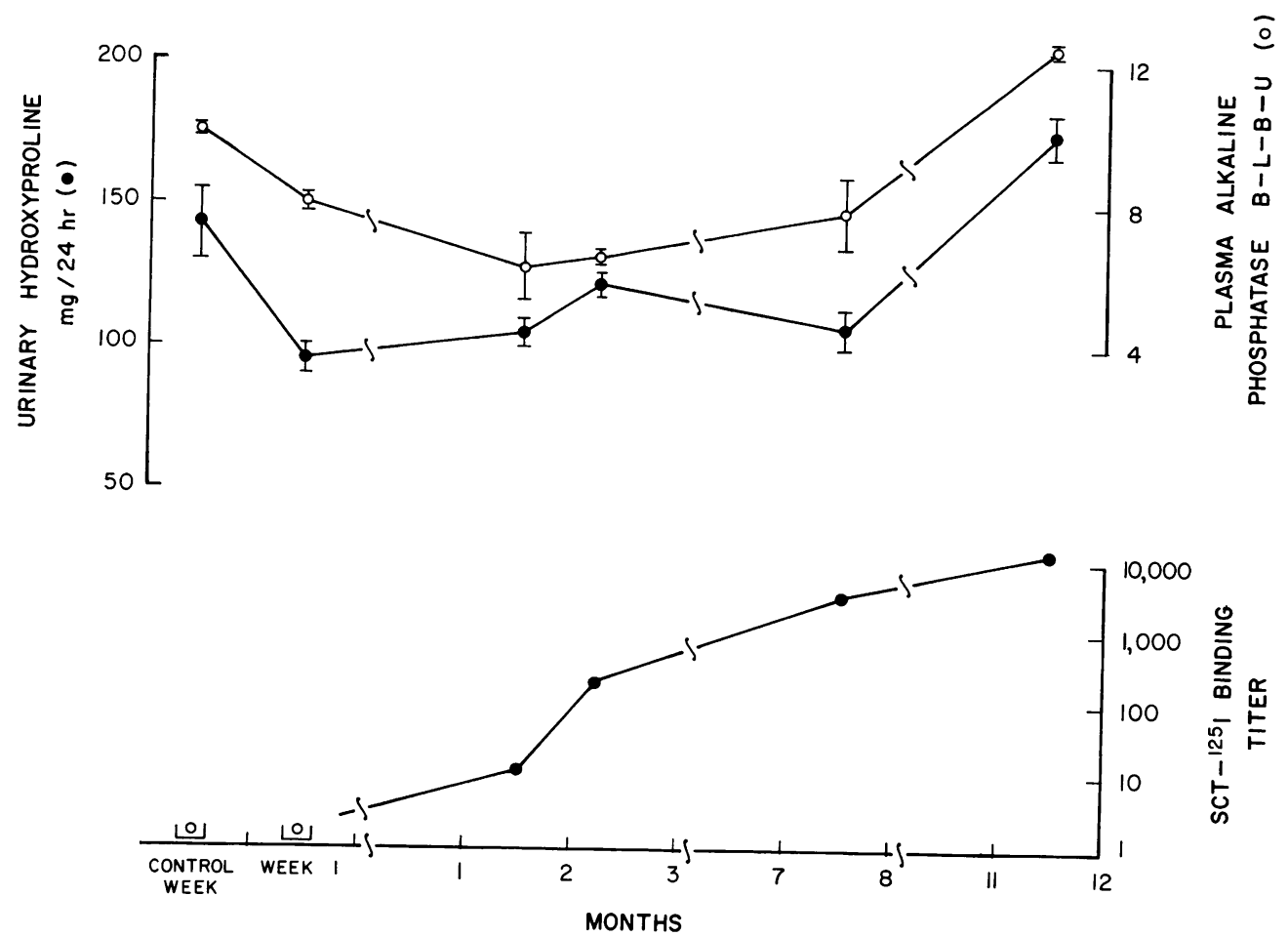

FIgUre 1 The control and treatment levels of urinary hydroxyproline, plasma alkaline phosphatase, and salmon calcitonin- ${ }^{125} \mathrm{I}$ binding titer during an 11.5 month period when patient $\mathrm{W}$. O. received $100 \mathrm{MRC}$ units of salmon calcitonin daily. The hydroxyproline data points represent the mean $\pm \mathrm{SE}$ of at least five $24 \mathrm{hr}$ urine collections during a 1 wk period. The upper limit of normal is $40 \mathrm{mg} / 24 \mathrm{hr}$. The alkaline phosphatase (Bessey-Lowry-Brock Units) data points represent the mean $\pm_{\mathrm{SE}}$ of at least three blood samples taken during the week. The upper limit of normal is $2.6 \mathrm{U}$. The binding titer is plotted on a log scale. 


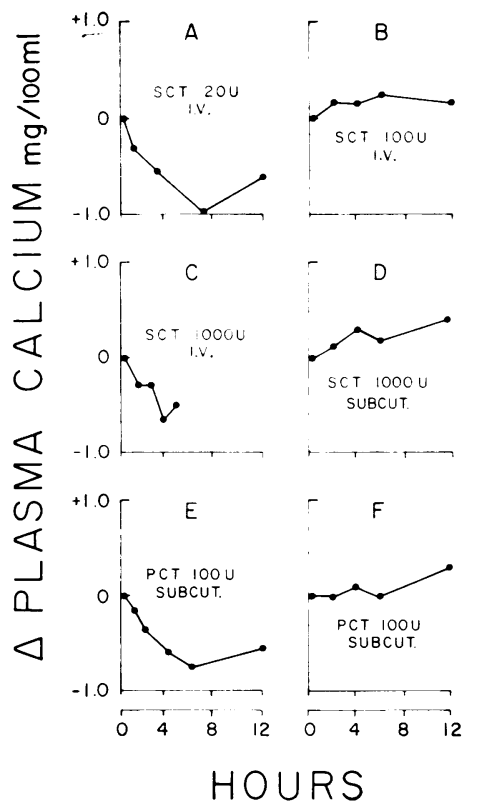

Figure 2 The plasma calcium responses to calcitonin during the course of treatment of patient W. O. $(A)$ Before salmon calcitonin treatment; $(B) 7$ months; $(C) 12$ months; $(D) 15$ months; $(E)$ before porcine calcitonin treatment; (F) 3 months.

During treatment there was neither clinical evidence of an allergic reaction or any evidence of renal, hepatic, or bone marrow toxicity. Plasma parathyroid hormone levels rose during the initial hypocalcemic period as well as during a similar period induced with 1000 MRC units of salmon calcitonin (cited above) after $1 \mathrm{yr}$ of treatment (Fig. 3). The levels of parathyroid hormone attained were similar on both occasions. Basal plasma calcium and phosphorus levels did not change significantly during treatment. There was no detectable radiologic change. The patient's bone pain diminished initially and did not return during the period in which he no longer showed a biochemical response to salmon calcitonin.

After 15 months of treatment with salmon calcitonin it was demonstrated that porcine calcitonin ${ }^{4}$ could produce a hypocalcemic response in the patient (Fig. 2E). $\mathrm{He}$ was then treated daily with 100 MRC units subcutaneously for 3 months. At the end of this period of treatment, his alkaline phosphatase and hydroxyproline excretion had not changed significantly from control levels, and he had become resistant to the hypocalcemic effect of porcine calcitonin (Fig. $2 F$ ). Plasma binding titers of porcine calcitonin $-{ }^{125} \mathrm{I}$ were measured using the same method as for salmon calcitonin ${ }^{-25} I$. At the onset of porcine calcitonin therapy, the porcine calcitonin $-{ }^{125} \mathrm{I}$

${ }^{4}$ AL0831 (Armour Pharmaceutical Co.). binding titer was $1: 300$, indicating that the antisalmon calcitonin antibody also bound porcine calcitonin. At the end of the 3 months of porcine calcitonin therapy, the titer had not changed significantly.

In three patients (P. S., G. Z., and L. H.) plasma alkaline phosphatase and urinary hydroxyproline either fell into the normal range or progressively fell toward normal. Five patients (A. M., J. A., H. H., A. F., and G. C.) showed a $25-75 \%$ decrease in skeletal turnover which persisted with continued treatment. These five patients continued to show an acute hypocalcemic response to injected salmon calcitonin throughout the course of treatment. There was no correlation between the development of antibodies and a plateau response. In the remaining patients there was a similar decrease in skeletal turnover but the duration of therapy or frequency of follow-up admissions was insufficient to establish whether these patients attained a plateau response.

Characterization of binding activity: association with immunoglobulin $G$. Control and treatment plasma from patients W. O., A. M., A. F., H. H., and R. W. was mixed with salmon calcitonin ${ }^{-125} \mathrm{I}$ and subjected to agarose gel electrophoresis. Radioautography revealed binding to the $\gamma$-globulin fraction in each of the five treatment plasmas; no binding was detected in any control plasma.

The same plasma samples were subjected to immunoelectrophoresis. After $\gamma \mathrm{G}, \gamma \mathrm{A}$, and $\gamma \mathrm{M}$ precipitin lines had formed, salmon calcitonin $-{ }^{125} \mathrm{I}$ was added to the troughs for radioautography. In Fig. $4 A$ and $B$ the results obtained with plasma from patient W. O. are shown. There was no difference in the precipitin lines

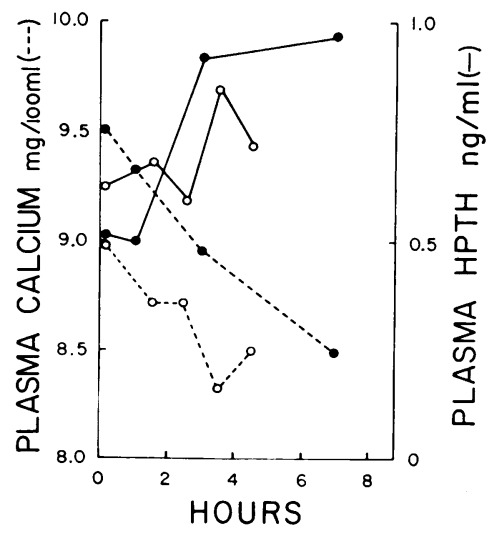

Figure 3 Plasma calcium and human parathyroid hormone levels in patient W. O. Our normal range for calcium is 8.5 to $10.5 \mathrm{mg} / 100 \mathrm{ml}$ and for parathyroid hormone 0.3 to $0.8 \mathrm{ng} / \mathrm{ml}$. The closed circles indicate the levels after the first injection of salmon calcitonin (20 MRC units i.v.). The open circles indicate the levels after the 1000 MRC unit i.v. salmon calcitonin dose at 12 months. 


\section{Pre}

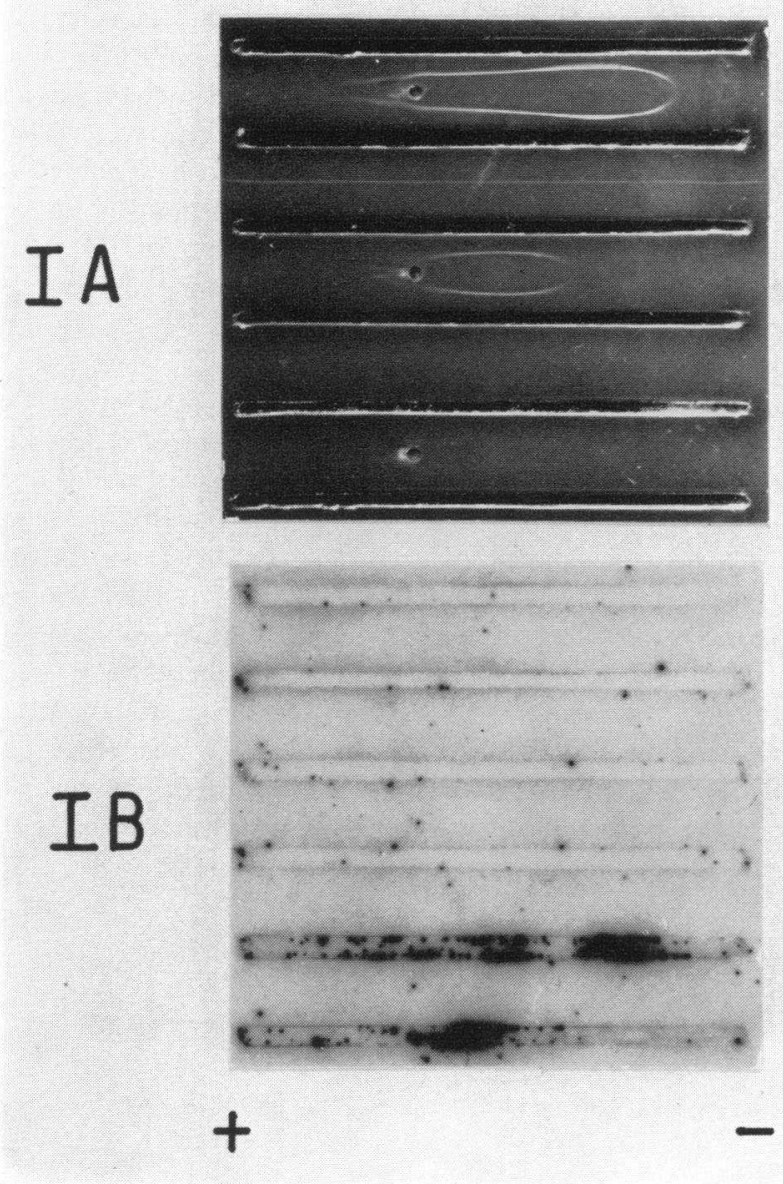

Post
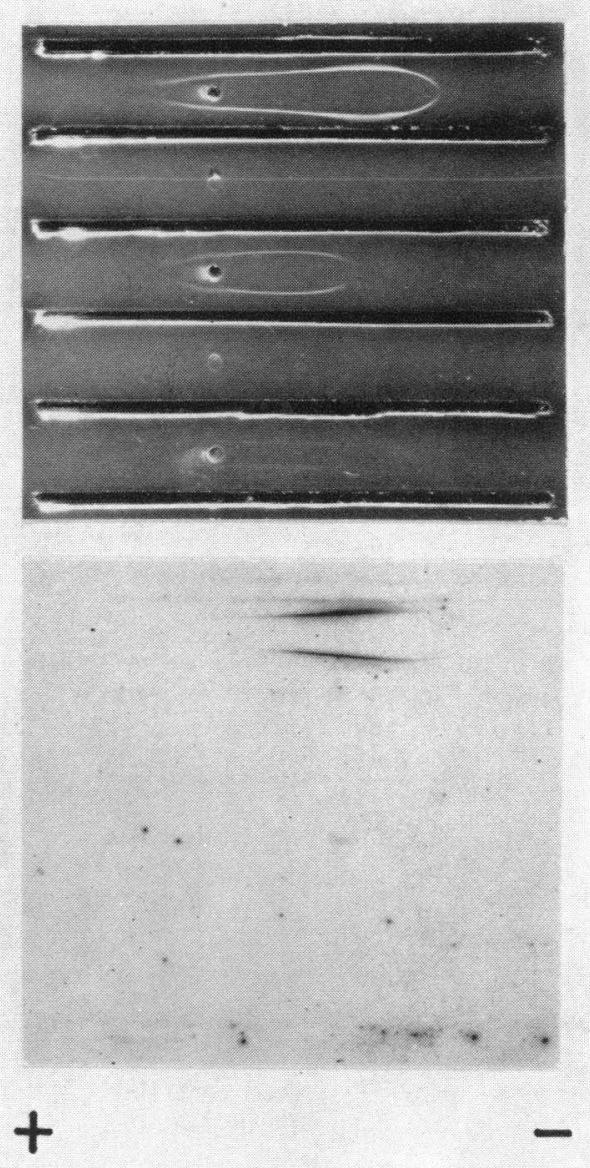

FIGURE 4 Immunoelectrophoresis and radioautography of plasma before and 12 months after the administration of salmon calcitonin to patient $W$. O. Wells contain pre- and post-treatment plasmas as indicated; troughs were filled with monospecific antiserum to human $\gamma \mathrm{G}$ (upper two troughs), antiserum to $\gamma \mathrm{A}$ (middle two troughs), and antiserum to $\gamma \mathrm{M}$ (lower two troughs). After development of precipitin lines (IA), salmon calcitonin ${ }^{-125} \mathrm{I}$ was added to the troughs; binding of labeled hormone primarily to the "fast" portion G precipitin arc occurred in the post-treatment plasma (IB).

observed with plasma obtained before and after therapy; salmon calcitonin- ${ }^{125} \mathrm{I}$ was bound to the $\gamma \mathrm{G}$ precipitin arc obtained with treatment plasma, but not with the control plasma. Identical results were obtained with the treatment plasma of the other patients.

Maximum binding capacity of $W$. O. plasma. The maximum binding capacity of the plasma of W. O. is illustrated in Fig. 5. The plasma taken after $1 \mathrm{yr}$ of salmon calcitonin therapy bound approximately $0.6 \mu \mathrm{g} /$ $\mathrm{ml}$, or $1.5 \mathrm{MRC}$ units $/ \mathrm{ml}$ of salmon calcitonin. If one assumes a volume of distribution of $\gamma \mathrm{G}$ antibody of 85 $\mathrm{ml}$ per kilogram of body weight (20), it can be calculated that approximately 10,000 MRC units of ad- ministered salmon could be bound by the total amount of antibody estimated to be present in patient W. O., who weighed $80 \mathrm{~kg}$.

Inactivation of hypocalcemic activity of salmon calcitonin by $W$. O. plasma. The results of an additional method of estimating the total amount of antibody present in patient W. O. are illustrated in Fig. 6. This method provides an approach that assesses directly inactivation of hormone by antibody rather than binding of hormone to antibody. Increasing quantities of the patient's plasma produced progressively greater inhibition of the hypocalcemic effect of salmon calcitonin in the rat. $500 \mu \mathrm{l}$ of plasma (the $1: 10$ dilution, Fig. 6) 


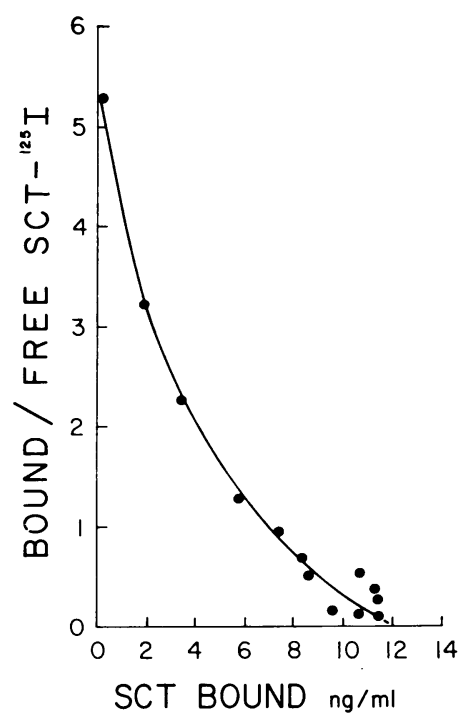

Figure 5 The maximum binding capacity of a $1: 50$ dilution of plasma from patient W. O. after 12 months of salmon calcitonin therapy. The ratio of salmon calcitonin${ }^{125} \mathrm{I}$ bound by antibody to free salmon calcitonin- ${ }^{125} \mathrm{I}$ is plotted as a function of bound salmon calcitonin. The maximum binding capacity is obtained by extrapolating the curve to the abscissa.

completely inhibited the hypocalcemic effect of 10 mMRC units of salmon calcitonin in a $100 \mathrm{~g}$ rat. When the data are plotted as per cent of hypocalcemic inhibition vs. the plasma dilution on a $\log$ scale, a linear regression is found (inset, Fig. 6). By extrapolating the line, it would appear that $100 \%$ inhibition could be achieved with plasma diluted $1: 15$. This figure is in good agreement with the direct observations that complete inactivation occurs with plasma diluted $1: 10$, and incomplete inactivation with plasma diluted $1: 20$. From this estimate it was calculated that $1 \mathrm{ml}$ of plasma from W. O. inactivates $0.3 \mathrm{MRC}$ units $(15 \times 20 \mathrm{mMRC}$ units $/ \mathrm{ml}$ ) of salmon calcitonin. It was further estimated, using the assumptions outlined above, that 2000 MRC units of calcitonin could be inactivated by the total quantity of antibody available in patient W. O. No inactivation of the biological activity of calcitonin was detected with the control plasma from this patient, or with plasma from five other patients (A. M., R. W., H. H., A. F., and G. C.).

\section{DISCUSSION}

The daily administration of salmon calcitonin to 22 patients for periods up to 19 months was associated with the development of plasma binding of salmon calcitonin${ }^{125} \mathrm{I}$ in 11 patients. The evidence that antibodies to salmon calcitonin were responsible for the binding included: $(a)$ the binding of salmon calcitonin- ${ }^{125} \mathrm{I}$ was demonstrated only after treatment with this hormone began; $(b)$ the salmon calcitonin ${ }^{-125} \mathrm{I}$ could be displaced from its binding sites by excess unlabeled salmon calcitonin; and (c) the binding activity was specifically associated with the IgG fraction of the plasma proteins as determined by radioimmunoelectrophoresis.

The clinical significance of the presence of antibodies, other than inhibition of the pharmacologic effect of salmon calcitonin in one patient, appears to be minimal in view of the lack of associated allergic phenomena or any evidence of toxicity. All patients, except W. O., continued to show a response to the hormone during the course of treatment as judged by continued suppression of the indices of skeletal turnover.

The clinical course of patient W. O. is of great interest since in this patient the development of antibodies appeared responsible for acquired resistance to the hormone. The unique features seen in this patient included: (a) the development of resistance to the biological effects of salmon calcitonin with the loss of the hypocalcemic response to the hormone and a return of indices of skeletal turnover to pretreatment values despite continued treatment; (b) a far greater antibody titer (maximum $1: 30,000$ ) than was found in any other patient; and $(c)$ inactivation by his plasma of salmon calcitonin in the rat bioassay. There was no clinical evi-

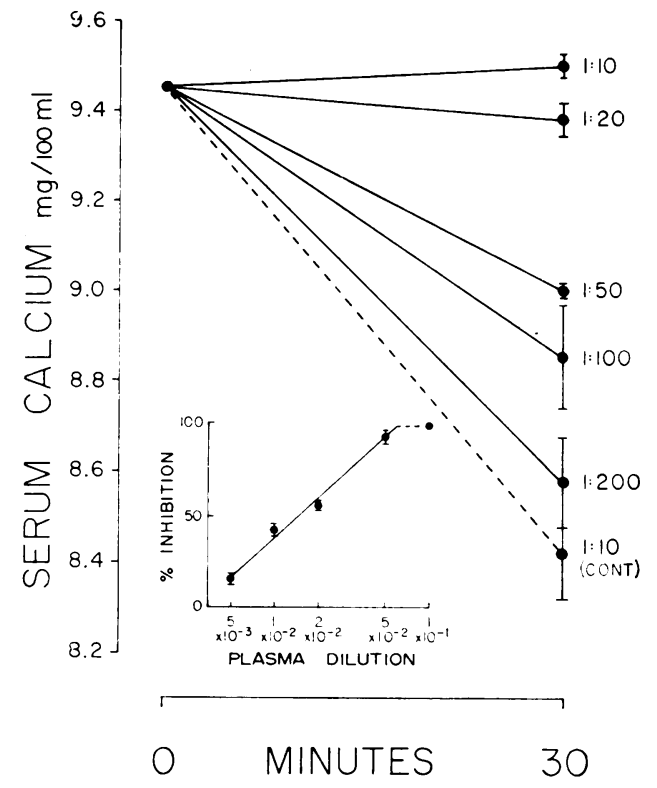

FIgURE 6 The inhibition of the hypocalcemic activity of salmon calcitonin by the plasma of patient W. O. The serum calcium (mean $\pm \mathrm{SE}$ of three separate studies) before and $30 \mathrm{~min}$ after injection of $10 \mathrm{mMRC}$ units (20 mMRC units/ $\mathrm{ml})$ salmon calcitonin $/ 100 \mathrm{~g}$ rat and varying dilutions of W. O. treatment plasma and plasma from a normal control. The inset shows the data plotted as the per cent inhibition of the maximal hypocalcemic response (the dashed line) vs. the plasma dilution on a log scale. 
dence of hyperparathyroidism and the concentrations of parathyroid hormone induced by hypocalcemia were similar before and during treatment. Hence, resistance to the hormone in this patient can not be attributed to the development of secondary hyperparathyroidism. It was possible to overcome resistance to the hypocalcemic effect of salmon calcitonin by rapid i.v. administration of $1000 \mathrm{MRC}$ units of the hormone. One speculation for this difference in response to subcutaneous and i.v. administration is that after i.v. injection enough hormone reached skeletal receptor sites before complete mixing of the hormone and antibody occurred.

Antibodies to polypeptide hormones have been demonstrated in the blood of patients treated with bovine and porcine insulin (21), bovine and porcine vasopressin (22), bovine parathyroid hormone (23), porcine and a1-24 ACTH $(24,25)$, and human growth hormone (26). Almost all diabetics treated with bovine and porcine insulin develop antibodies to insulin, but only a few are insulin resistant. Berson and Yalow have pointed out that the responsive diabetics with antibodies have low binding capacities and that the insulin-resistant patients have much greater binding capacities (13). Resistance to vasopressin has not been documented and only one patient with antibodies and resistance to bovine $\mathrm{PTH}$ has been described (23). Antibodies to porcine ACTH given in gelatin and as a zinc phosphate complex commonly result in antibody formation, but resistance to hormone action has not been proven $(24,25)$. In these reports the foreign protein nature of the hormones has been used as the explanation for the development of antibodies. Development of antibodies to hormone preparations believed to be identical to endogenous human hormone would appear to violate concepts of immune tolerance. However, synthetic $\alpha 1-24$ ACTH did induce antibody formation in man although this polypeptide is identical in structure to the first 24 amino acids of human ACTH (25). Lack of the terminal 15 amino acids may unmask an antigenic site in this peptide. Human growth hormone administration can also result in antibody formation and resistance to its metabolic effects in man $(27,28)$. Conformational differences resulting from extraction of growth hormone from pituitary glands may render this preparation antigenic in man.

Once resistance to salmon calcitonin developed in patient W. O. who had initially responded to the hormone, it seemed reasonable to administer to him another form of calcitonin that is structurally distinct, such as porcine calcitonin. However, since porcine calcitonin is quite different in structure from human calcitonin (5), it might be expected that antibodies directed against this hormone would also develop. Patient W. O., who already had a low titer of antibodies which bound porcine calcitonin, received treatment for 3 months with the hormone after it was demonstrated that he was not resistant to its hypocalcemic effect. He became resistant to porcine calcitonin during this period although he did not show a rise in antibody titer. Further studies are required to elucidate the mechanism of clinical resistance developing during treatment with porcine calcitonin in this patient.

Human calcitonin has recently become available for therapeutic trials. However, since the structure of synthetic human calcitonin is based on the structure determined from calcitonin extracted from a medullary carcinoma of thyroid (29), it is possible that there is a small difference in structure between the synthetic preparation and endogenous calcitonin in normal subjects. Such a difference could predispose to antibody development to human tumor calcitonin in patients treated with this preparation. In a recent paper the absence of antibody formation was reported in one patient treated with human calcitonin for $1 \mathrm{yr}$ (3). Recently we have started to administer synthetic human calcitonin ${ }^{5}$ to patient W. O. Preliminary results indicate a definite decrease in skeletal turnover during the 1 st wk of treatment.

Note added in proof. After 6 months of treatment with human calcitonin the plasma alkaline phosphatase and $24 \mathrm{hr}$ urinary hydroxyproline excretion of patient W. O. had plateaued at two to three times normal. These indices had decreased $40 \%$ from control levels. There were no detectable antibodies to human calcitonin in his plasma and there was no evidence for hyperparathyroidism. The factor responsible for the incomplete suppression of his disease remains to be determined.

\section{ACKNOWLEDGMENTS}

We thank Dr. James Lesh, James Bastian, and Karl Hansen of Armour Pharmaceutical for the salmon and porcine calcitonin, and Doctors Alfred Ling and William Darrow of Ciba for the human calcitonin, and Elizabeth Greene, Michael Byrne, Phillip Nagel, and Cyrena Simons for expert technical assistance. This study was supported by grants from the Veterans Administration, John A. Hartford Foundation, Gebbie Foundation, Damon Runyon Memorial Fund for Cancer Research, and U. S. Public Health Service (AM03564, AM11794, AM05205, and AM04501).

${ }^{5}$ Calcitonin M (Ciba Pharmaceutical Co., Summit, N. J.).

\section{REFERENCES}

1. Foster, G. V., G. F. Joplin, I. MacIntyre, K. E. W. Melvin, and E. Slack. 1966. Effect of thyrocalcitonin in man. Lancet. I : 107.

2. Bijvoet, O. L. M., J. van der Sluys Veer, J. Wildiers, and O. Smeenk. 1969. Effects of long-term calcitonin administration to patients. In Calcitonin 1969, Proceedings of the Second International Symposium. S. Taylor and G. Foster, editors. W. Heinemann, London. 531.

3. Woodhouse, N. J. Y., M. Reiner, P. Bordier, D. N. Kalu, M. Fisher, G. V. Foster, G. F. Joplin, and I. MacIntyre. 1971. Human calcitonin in the treatment of Paget's bone disease. Lancet. I: 1139.

4. Singer, F. R., H. T. Keutmann, R. M. Neer, J. T. Potts, Jr., and S. M. Krane. 1972. Pharmacological 
effects of salman calcitonin in man. Calcium, Parathyroid Hormone and the Calcitonins. R. V. Talmage and P. L. Munson, editors. Excerpta Medica Foundation, Amsterdam. 89.

5. Potts, J. T., Jr., H. D. Niall, H. T. Keutmann, L. J. Deftos, and J. A. Parsons. 1969 Calcitonin: Recent chemical and immunological studies. In Calcitonin 1969, Proceedings of the Second International Symposium, S. Taylor and G. Foster, editors. W. Heinemann, London, 56.

6. Aldred, J. P., G. R. Clements, R. J. Schlueter, J. W. Bastian, J. P. Dailey and F. X. Wazeter. 1968. Pharmacologic and toxicologic effects of porcine thyrocalcitonin in animals. In Calcitonin, Proceedings of the Symposium on Thyrocalcitonin and the C Cells. S. Taylor, editor. W. Heinemann, London. 373.

7. MacIntyre, I. 1961. Flame photometry. Adv. Clin. Chem. 4:1.

8. Prockop, D. J., and S. Udenfriend. 1960. A specific method for the analysis of hydroxyproline in tissues and urine. Anal. Biochem. 1:228.

9. Bessey, O. A., O. H. Lowry, and M. J. Brock. 1946. A method for the rapid determination of alkaline phosphatase with five cubic millimeters of serum. J. Biol. Chem. 164: 321.

10. Potts, J. T., Jr., and L. J. Deftos. 1969. Parathyroid hormone, thyrocalcitonin, vitamin $\mathrm{D}$, bone and bone mineral metabolism. In Duncan's Diseases of Metabolism. P. K. Bondy, editor. W. B. Saunders Co., Philadelphia. 6th edition.

11. Hunter, W. M., and F. C. Greenwood. 1962. Preparation of iodine-131 labelled human growth hormone of high specific activity. Nature (Lond.). 194: 495.

12. Rosselin, G., R. Assan, R. S. Yalow, and S. A. Berson, 1966. Separation of antibody-bound and unbound peptide hormones labelled with ${ }^{131} \mathrm{I}$ by talcum powder and precipitated silica. Nature (Lond.). 212: 355.

13. Berson, S. A., and R. S. Yalow. 1959. Quantitative aspects of the reaction between insulin and insulin-binding antibody. J. Clin. Invest. 38: 1996.

14. Laurell, C. B. 1965. Electrophoretic microheterogeneity of serum a1-antitrypsin. Scand. J. Clin. Lab. Invest. $17: 271$.

15. Bloch, K. J., H. C. Morse III, and K. F. Austen. 1968. Biological properties of rat antibodies. I. Antigen binding by four classes of anti-DNP antibodies. J. Immunol. $101: 650$.

16. Fahey, J. L., and C. McLaughlin. 1963. Preparation of antisera specific for $6.6 \mathrm{~S} \gamma$-globulin, $\beta_{2 \mathrm{~A}}$-globulins, $\gamma 1$ - microglobulins, and for type I and II common $\gamma$ globulin determinants. J. Immunol. 91: 484.

17. Tashjian, A. H., Jr., and E. F. Voelkel. 1968. Studies of the inactivation of thyrocalcitonin by serum. In Parathyroid Hormone and Thyrocalcitonin (Calcitonin), Proceedings of the Third Parathyroid Conference. $R$. V. Talmage and L. F. Belanger, editors. Excerpta Medica Foundation, Amsterdam. 108.

18. Schlueter, R. J., J. P. Aldred, and J. D. Fisher. 1968. Thyrocalcitonin-bioassay characteristics of purified preparations. Acta Endocrinol. 58: 268.

19. Gitelman, H. J. 1967. An improved automated procedure for the determination of calcium in biological specimens. Anal. Biochem. 18: 521.

20. Waldmann, T. A., and W. Strober. 1969. Metabolism of immunoglobulins. Prog. Allergy. 13: 1.

21. Berson, S. A., R. S. Yalow, A. Bauman, M. A. Rothschild, and K. Newerly. 1956. Insulin ${ }^{131} \mathrm{I}$ metabolism in human subjects: demonstration of insulin binding globulin in the circulation of insulin treated subjects. J. Clin. Invest. $35: 170$.

22. Roth, J., S. M. Glick, L. A. Klein, and M. J. Peterson. 1966. Specific antibody to vasopressin in man. J. Clin. Endocrinol. Metab. 26: 671.

23. Melick, R. A., J. R. Gill, Jr., S. A. Berson, R. S. Yalow, F. C. Bartter, J. T. Potts, Jr., and G. D. Aurbach. 1967. Antibodies and clinical resistance to parathyroid hormone. N. Engl.J. Med. 276: 144.

24. Fleischer, N., K. Abe, G. W. Liddle, D. N. Orth, and W. E. Nicholson. 1967. ACTH antibodies in patients receiving depot porcine $\mathrm{ACTH}$ to hasten recovery from pituitary-adrenal suppression. J. Clin. Invest. 46: 196.

25. Ratcliffe, J. G., M. Pritchard, and A. H. El-Shaboury. 1969. The production of antibodies to porcine corticotrophin and to synacthen. J. Endocrinol. 43: 1.

26. Roth, J., S. M. Glick, R. S. Yalow, and S. A. Berson. 1964. Antibodies to human growth hormone in human subjects treated with HGH. J. Clin. Invest. 43: 1056.

27. Parker, M. L., I. K. Mariz, and W. H. Daughaday. 1964. Resistance to human growth hormone in pituitary dwarfs: Clinical and immunologic studies. J. Clin. Endocrinol. Metab. 24 : 997.

28. Prader, A., H. Wagner, J. Szeky, R. Illey, J. L. Tauber, and D. Maingay. 1964. Acquired resistance to human growth hormone caused by specific antibodies. Lancet. I : 378 .

29. Neher, R., B. Riniker, R. Maier, P. G. H. Byfield, T. V. Gudmundsson, and I. MacIntyre. 1968. Human calcitonin. Nature (Lond.). 220: 984. 